\title{
Hypoglycemia in Type 1 Diabetes Mellitus*
}

\author{
Philip E. Cryer, M.D. \\ Irene E. and Michael M. Karl Professor of Endocrinology and Metabolism in Medicine, \\ Washington University in St. Louis and Physician, Barnes-Jewish Hospital, St. Louis, Missouri
}

\section{Synopsis}

Iatrogenic hypoglycemia, typically the result of the interplay of therapeutic hyperinsulinemia and compromised defenses resulting in hypoglycemia-associated autonomic failure (HAAF) in diabetes, is a problem for people with T1DM. It causes recurrent morbidity and is sometimes fatal, leads to recurrent hypoglycemia, and precludes euglycemia over a lifetime of T1DM. Risk factors include those that result in relative or absolute insulin excess and those indicative of HAAF in diabetes including absolute endogenous insulin deficiency, a history of severe hypoglycemia, hypoglycemia unawareness, or both, and lower glycemic goals. Minimizing the risk of hypoglycemia involves matching insulin action and glucose availability and four specific steps: 1) acknowledge the problem, 2) apply the principles of aggressive glycemic therapy, 3) consider the conventional risk factors, and 4) consider the risk factors indicative of HAAF. Treatment of hypoglycemia is usually accomplished by ingestion of carbohydrate by the patient. Sometimes it involves administration of glucagon or infusion of glucose by others. Elimination of hypoglycemia from the lives of people with T1DM will likely be accomplished by new treatment methods that provide plasma glucose regulated insulin replacement or secretion.

\section{Keywords}

Hypoglycemia; Diabetes; Defective Glucose Counterregulation; Hypoglycemia Unawareness; Hypoglycemia-Associated Autonomic Failure in Diabetes

\section{The Limiting Factor in Glycemic Control}

The clinical problem of hypoglycemia in diabetes has been summarized [1] and discussed in detail [2]. Because it reduces microvascular complications [3] - retinopathy, nephropathy and neuropathy - and may reduce macrovascular complications [4], glycemic control is

\footnotetext{
*An invited chapter for Type 1 Diabetes. Schatz D, Haller J, Atkinson M (eds). Endocrinology and Metabolism Clinics of North America.

(C) 2010 Elsevier Inc. All rights reserved.

Correspondence: Philip E. Cryer, M.D. Campus Box 8127 Washington University School of Medicine 660 South Euclid Avenue St. Louis, MO 63110 (314) 362-7635 (314) 362-7989 (fax) pcryer@wustl.edu.

This chapter was written shortly after the publication of the author's book Hypoglycemia in Diabetes: Pathophysiology, Prevalence and Prevention, American Diabetes Association, Alexandria, Virginia, 2009 (2). Therefore, much of the factual and interpretive content here is the same, as is no small part of the phraseology.

The author has served as a consultant to several pharmaceutical or device firms including Amgen Inc., Johnson \& Johnson, MannKind Corp., Marcadia Biotech, Medtronic MiniMed Inc., Merck and Co., Novo Nordisk A/S, Takeda Pharmaceuticals North America, and TolerRx Inc. in recent years. He does not receive research funding from, hold stock in or speak for any of these firms.

Publisher's Disclaimer: This is a PDF file of an unedited manuscript that has been accepted for publication. As a service to our customers we are providing this early version of the manuscript. The manuscript will undergo copyediting, typesetting, and review of the resulting proof before it is published in its final citable form. Please note that during the production process errors may be discovered which could affect the content, and all legal disclaimers that apply to the journal pertain.
} 
generally in the best interest of people with type 1 diabetes mellitus (T1DM). However, iatrogenic hypoglycemia is the limiting factor in the glycemic management of T1DM [1,2]. It 1) causes recurrent morbidity in most people with T1DM, and is sometimes fatal, 2) impairs defenses against subsequent hypoglycemia and therefore causes a vicious cycle of recurrent hypoglycemia, and 3) precludes maintenance of euglycemia over a lifetime of diabetes and thus full realization of the benefits of glycemic control. Euglycemia is not an appropriate glycemic goal in the vast majority of people with T1DM [1,2]. Perhaps a reasonable goal is the matching of exogenous insulin actions and circulating glucose availability that results in the lowest mean glycemia (e.g., $\mathrm{HbA}_{1 \mathrm{C}}$ ) that causes no severe hypoglycemia, permits continued awareness of hypoglycemia and produces a tolerable number of episodes of symptomatic hypoglycemia.

\section{Incidence and Impacts of Hypoglycemia in T1DM}

Iatrogenic hypoglycemia is a fact of life for people with T1DM [1,2]. They suffer untold numbers of episodes of asymptomatic hypoglycemia. In one study of subcutaneous glucose sensing in T1DM glucose levels were $\leq 70 \mathrm{mg} / \mathrm{dL}$ ( $3.9 \mathrm{mmol} / \mathrm{L}) 1.5$ hours per day (i.e., $6.3 \%$ of the time) [5]. In a study involving nocturnal plasma glucose measurements every 15 minutes in T1DM, glucose levels were $<70 \mathrm{mg} / \mathrm{dL}$ in $57 \%$ (12 of 21) of the patients [6]. Many of these episodes are asymptomatic but they are not benign because they impair physiological and behavioral defenses against subsequent hypoglycemia [1,2]. People with T1DM suffer an average of two episodes of symptomatic hypoglycemia per week thousands of such episodes over a lifetime of diabetes. They suffer an average of approximately one episode of severe, at least temporarily disabling, hypoglycemia, often with seizure or coma, per year [1,2].

Falling plasma glucose concentrations normally signal a series of responses including a decrease in insulin secretion as glucose levels decline within the physiological range, increases in glucagon and epinephrine secretion as glucose levels fall below the physiological range, and a more intense sympathoadrenal response with symptoms at plasma glucose levels of 50-55 mg/dL (2.8-3.0 mmol/L) [1,2]. Neurogenic (autonomic) symptoms (catecholamine mediated or adrenergic: tremor, palpitations and anxiety/arousal and acetylocholine mediated or cholinergic: sweating, hunger, and paresthesias) are the result of the perception of physiological changes caused by sympathoadrenal, largely sympathetic neural [7], activation [8]. Neuroglycopenic symptoms (cognitive impairments, behavioral changes and psychomotor abnormalities and at lower glucose levels seizure and coma) are the result of brain glucose deprivation per se. The glycemic thresholds for these responses are dynamic [1,2]. They shift to higher plasma glucose concentrations in people with poorly controlled T1DM $[9,10]$ and to lower plasma glucose concentrations in those with well controlled T1DM [10].

Functional brain failure caused by hypoglycemia is typically corrected after the plasma glucose concentrations is raised $[1,2,11]$. Rarely, hypoglycemia causes sudden, presumably cardiac arrhythmic, death or, if it is prolonged and profound, brain death [11-13]. Early reports suggested that $2 \%$ to $4 \%$ of deaths of people with diabetes are the result of hypoglycemia [1,2]. More recent reports indicate that $6 \%$ to $10 \%$ of deaths of people with T1DM are caused by hypoglycemia [14-16]. Regardless of the exact rates, the existence of iatrogenic mortality is alarming.

\section{Definition of Hypoglycemia in T1DM}

The American Diabetes Association (ADA) Workgroup on Hypoglycemia defined hypoglycemia in people with diabetes as "all episodes of abnormally low plasma glucose concentration that expose the individual to potential harm"[17]. That includes episodes of 
asymptomatic hypoglycemia since those impair defenses against subsequent hypoglycemia $[1,2]$. It is not possible to state a specific plasma glucose concentration that defines hypoglycemia because the glycemic thresholds for symptoms, among other manifestations, are dynamic $[9,10]$. Nonetheless, the ADA Workgroup recommended that people with T1DM become concerned about the possibility of hypoglycemia at a self-monitored (or glucose sensing device estimated) plasma glucose concentration of $\leq 70 \mathrm{mg} / \mathrm{dL}(3.9 \mathrm{mmol} / \mathrm{L})$ [17]. The rationale for that cut-off value is that, within the error of these measurements, 70 $\mathrm{mg} / \mathrm{dL}$ approximates the lower limit of the postabsorptive plasma glucose concentration range and the glycemic threshold for activation of glucose counterregulatory systems and is the highest low level reported to reduce counterregulatory responses to subsequent hypoglycemia in nondiabetic individuals [17]. However, that recommendation does not mean that patients should always self-treat at a glucose level of $\leq 70 \mathrm{mg} / \mathrm{dL}(3.9 \mathrm{mmol} / \mathrm{L})$ [18]. The options include repeating the measurement in the near term (or observing the trend with a device), avoiding a critical task such as driving, ingesting carbohydrates and using the information to adjust the subsequent therapeutic regimen.

The ADA Workgroup also suggested a classification of hypoglycemia in diabetes [17]. That includes 1) severe hypoglycemia (an event requiring assistance of another person to raise glucose levels and promote neurological recovery), 2) documented symptomatic hypoglycemia (symptoms plus low glucose) and 3) asymptomatic hypoglycemia (low glucose without symptoms) as well as 4) probable symptomatic hypoglycemia (symptoms without a glucose estimate) and 4) relative hypoglycemia (symptoms with glucose levels that are not low but are approaching that level).

\section{Physiology of Glucose Counterregulation (Fig. 1)}

The physiological defenses against falling plasma glucose concentrations in nondiabetic individuals include 1) decrements in pancreatic $\beta$-cell insulin secretion, 2) increments in pancreatic $\alpha$-cell glucagon secretion and, absent the latter, 3 ) increments in adrenomedullary epinephrine secretion $[1,2,19]$. Lower insulin levels favor increased glucose production which is also stimulated by glucagon and epinephrine. Epinephrine also limits glucose utilization and mobilizes gluconeogenic precursors; it normally inhibits insulin secretion although it cannot do so in T1DM [19]. The behavioral defense is carbohydrate ingestion prompted by symptoms that are largely sympathoadrenal, predominantly sympathetic neural $[1,2,7,8,19]$, in origin. All of these defenses are typically compromised in people with T1DM [1,2,20,21].

\section{Pathophysiology of Glucose Counterregulation in T1DM (Fig. 1 and 2)}

All insulin preparations are pharmacokinetically imperfect. Thus, episodes of therapeutic hyperinsulinaemia occur from time-to-time in T1DM. These cause declining plasma glucose concentrations that may, if not effectively countered, result in hypoglycemia. Absolute therapeutic insulin excess of sufficient magnitude can cause an isolated episode of hypoglycemia despite intact glucose counterregulatory defenses [1,2] (Fig. 2). But, hypoglycemia is more commonly the result of the interplay of relative or mild-to-moderate absolute therapeutic insulin excess and compromised physiological and behavioral defenses against falling plasma glucose concentrations in T1DM [1,2,20,21] (Fig. 1 and Fig. 2).

\section{Defective Glucose Counterregulation and Hypoglycemia Unawareness}

In established T1DM the first and second physiological defenses against hypoglycemia - a decrease in insulin and an increase in glucagon - are lost, and the third physiological defense - an increase in epinephrine - is often attenuated [1,2,20,21]. Loss of the endogenous insulin response is the result of $\beta$-cell failure, the basic cause of T1DM. Loss of 
the glucagon response [22] is also likely the result of $\beta$-cell failure [1,2] since a decrease in $\beta$-cell secretion of insulin, perhaps among other secretory products, in concert with hypoglycemia, normally signals increased $\alpha$-cell glucagon secretion [23,24]. Although it can be caused by recent antecedent hypoglycemia [25], or by prior exercise or by sleep [1,2], the mechanism of the attenuated sympathoadrenal response to falling glucose levels is not known [1,2]. In the setting of therapeutic hyperinsulinaemia and falling plasma glucose concentrations and absent insulin and glucagon secretory responses, the attenuated epinephrine response causes the clinical syndrome of defective glucose counterregulation $[1,2,21,25]$ which is associated with a 25-fold [26] or greater [27] increased risk of severe iatrogenic hypoglycemia. The attenuated sympathoadrenal response, largely attenuation of its sympathetic neural component [7], causes the clinical syndrome of hypoglycemia unawareness (or impaired awareness of hypoglycemia) and, thus, loss of the behavioral defense, carbohydrate ingestion $[1,2,21]$. Hypoglycemia unawareness is associated with a 6fold increased risk of iatrogenic hypoglycemia [28].

\section{Hypoglycemia-Associated Autonomic Failure}

The concept of hypoglycemia-associated autonomic failure (HAAF) in diabetes $[1,2,11,21]$ (Fig. 2) posits that recent antecedent hypoglycemia, or prior exercise or sleep, causes both defective glucose counterregulation (by attenuating increments in epinephrine in the setting of absent decrements in insulin and absent increments in glucagon during subsequent hypoglycemia) and hypoglycemia unawareness (by attenuating sympathoadrenal and resulting neurogenic symptom responses during subsequent hypoglycemia) and, thus, a vicious cycle of recurrent hypoglycemia. Perhaps the most convincing evidence of the clinical relevance of HAAF is the finding - originally in three independent laboratories [29-32] - that as little as 2-3 weeks of scrupulous avoidance of hypoglycemia reverses hypoglycemia unawareness, and improves the deficient epinephrine component of defective glucose counterregulation, in most affected patients.

The mechanism(s) of the attenuated sympathoadrenal response to falling plasma glucose concentrations, the key feature of HAAF, is unknown. Theories include effects of a systemic mediator such as cortisol on the brain, an increase in blood-to-brain transport of a metabolic fuel such as glucose among others, altered hypothalamic mechanisms and activation of an inhibitory cerebral network mediated through the thalamus $[1,2,33]$.

\section{Risk Factors for Hypoglycemia in T1DM}

\section{Conventional Risk Factors}

The conventional risk factors for hypoglycemia in diabetes are based on the premise that relative or absolute therapeutic hyperinsulinemia is the sole determinant of risk [1,2,34]. Relative - to low rates of glucose influx into the circulation, high rates of glucose efflux out of the circulation - or absolute therapeutic hyperinsulinaemia occurs when: 1) Insulin doses are excessive, ill-timed or of the wrong type. 2) Exogenous glucose delivery is decreased (as following missed meals or during the overnight fast or when glucose absorption is delayed as in gastroparesis or decreased as in celiac disease). 3) Glucose utilization is increased (as during and shortly after exercise). 4) Endogenous glucose production is decreased (as following alcohol ingestion). 5) Sensitivity to insulin is increased (as during the middle of the night or following weight loss, improved fitness or improved glycemic control). 6) Insulin clearance is decreased (as with renal failure). These risk factors must be considered carefully when hypoglycemia is a problem. However, aside from the first, they explain only a minority of episodes of hypoglycemia [35]. 


\section{Risk Factors for HAAF}

These [1,2,3,4] include: 1 ) The degree of absolute endogenous insulin deficiency. This determines the extent to which insulin levels do not decrease and glucagon levels do not increase as glucose levels fall in response to therapeutic hyperinsulinemia. 2) A history of severe hypoglycemia, hypoglycemia unawareness or both as well as recent antecedent hypoglycemia, prior exercise or sleep. A history of severe hypoglycemia documents, and that of hypoglycemia unawareness implies, recent antecedent hypoglycemia which, like prior exercise or sleep, causes attenuated sympathoadrenal and symptomatic responses to subsequent hypoglycemia, the key feature of HAAF. 3) Aggressive glycemic therapy per se (lower HbA1C levels, lower glycemic goals). Hypoglycemic can occur in patients with any $\mathrm{HbA}_{1 \mathrm{C}}$ level. Nonetheless, lower mean glycemia is a risk factor for hypoglycemia. Studies with a control group treated to a higher $\mathrm{HbA}_{1 \mathrm{C}}$ consistently report a higher rate of hypoglycemia in the patients treated to a lower $\mathrm{HbA}_{1 \mathrm{C}}$ [1-3]. That does not mean that one cannot improved glycemic control and minimize the risk of iatrogenic hypoglycemia in individual people with T1DM $[1,2,34]$.

\section{Minimizing the Risk of Hypoglycemia in T1DM}

Minimizing the risk of hypoglycemia in T1DM involves the practice of hypoglycemia risk factor reduction [1,2,34,36,37]. That includes four steps: 1) Acknowledge the problem. 2) Apply the principles of aggressive glycemic therapy. 3) Consider the conventional risk factors for hypoglycemia. 4) Consider the risk factors indicative of HAAF in diabetes.

\section{Acknowledge the Problem}

Patient concerns about the reality, or the possibility, of hypoglycemia can be a barrier to glycemic control [38]. Some are reluctant to raise the issue despite those concerns. Therefore, the issue of hypoglycemia should be addressed in every contact with a person with T1DM. In addition to questioning the patient and examining the self monitoring of blood glucose (SMBG) log (and any glucose sensing record), it is often helpful to question close associates of the patient.

\section{Apply the Principles of Aggressive Glycemic Therapy}

These, which have been reviewed [1,2,34,36,37], include: 1) Patient education and empowerment. 2) Frequent SMBG (and is some instances glucose sensing). 3) Flexible and appropriate insulin, among other, regimens. 4) Individualized glycemic goals. 5) Ongoing professional guidance and support.

Patient Education and Empowerment-Contemporary regimens for the treatment of T1DM are complex [34,36,37] and the glycemic management of T1DM becomes more challenging over time [39]. Successful glycemic management is largely dependent upon the skills and decisions of a well informed person with diabetes. Clearly, patient education and empowerment are fundamentally important.

In addition to the key relationship between exogenous insulin action and glucose availability in the circulation and the basic survival skills of diabetes, people with T1DM need to learn about the anticipation, recognition and treatment of hypoglycemia [40,41]. They need to know the common symptoms, and their most meaningful symptoms, of hypoglycemia, how to treat (and not over-treat) hypoglycemia and the risk factors for hypoglycemia. Close associates need to learn how to recognize severe hypoglycemia and how to administer glucagon. Patients need to know that increasing episodes of hypoglycemia signal an increasing likelihood of future, even more severe, hypoglycemia [41] and how to apply SMBG (and glucose sensing) data to the adjustment of their subsequent regimen. 
Frequent SMBG (and in some instance continuous glucose sensing)-Patients with T1DM should perform SMBG regularly and whenever they suspect hypoglycemia $[1,2]$. It is particularly important for them to check their glucose level before performing a critical task such as driving. SMBG permits documentation of hypoglycemia (or hyperglycemia), allows patients to correlate their symptoms and glucose levels and provides information that may lead to regimen adjustments that prevent hypoglycemia [41]. Continuous glucose sensing should reduce the risk of hypoglycemia without compromising glycemic control because it informs the patient whether the glucose level is stable, rising or falling. There appears to be steady progress with the devices, although compelling evidence of net benefit remains to be reported [5,42]. Ultimately, a continuous glucose monitoring device will be a component of a closed-loop insulin replacement system.

Flexible and Appropriate Insulin, Among Other, Regimens-Although a variety of combinations are used, contemporary insulin therapy of T1DM is basically a basal-bolus approach using either multiple daily injection (MDI) of insulin or continuous subcutaneous insulin infusion (CSII). The use of a long-acting basal insulin analogue (glargine, detemir) rather than NPH insulin in an MDI regimen reduces at least the incidence of nocturnal hypoglycemia, perhaps that of total and symptomatic hypoglycemia, in T1DM [43,44]. The use of a rapid acting prandial insulin analogue (lispro, aspart, glulisine) rather than regular insulin reduces the incidence of nocturnal hypoglycemia in T1DM [43,44]. Albeit conceptually attractive, the superiority of CSII with an insulin analogue over MDI with insulin analogues with respect to the incidence of hypoglycemia at comparable levels of glycemic control remains to be established convincingly [45,46]. That is also the case in pregnant women with diabetes [47].

Iatrogenic hypoglycemia often occurs at night, specifically during sleep [3,6,35,48,49]. In one study one quarter of youth with T1DM suffered nocturnal hypoglycemia [49]. In another over half of adults with T1DM had nocturnal plasma glucose levels less than $70 \mathrm{mg}$ / $\mathrm{dL}(3.9 \mathrm{mmol} / \mathrm{L})[6]$. Nighttime is typically the longest interval between SMBG and between eating, and is the time of maximal sensitivity to insulin. Furthermore, sleep causes a further reduced sympathoadrenal response to hypoglycemia [50,51]. Thus, sleeping patient with T1DM have both further reduced epinephrine responses to hypoglycemia [5,51], the key feature of defective glucose counterregulation, and reduced arousal from sleep [51,52], a form of hypoglycemia unawareness. They have sleep-related HAAF $[1,2,51]$ and are at high risk for hypoglycemia [6,49]. Approaches to the prevention of nocturnal hypoglycemia include the use of insulin analogues $[43,44]$ as mentioned earlier. Other approaches include attempts to provide sustained delivery of exogenous carbohydrate throughout the night $[1,2,6]$. Those include bedtime snacks and bedtime administration of uncooked cornstarch, both of which have been found to only shift episodes of hypoglycemia to later in the night [6]. Alternative approaches to the prevention of nocturnal hypoglycemia include attempts to provide sustained delivery of endogenous glucose throughout the night. Those include bedtime oral administration of the epinephrine simulating $\beta_{2}$-adrenergic agonist terbutaline $[6,53]$ and overnight glucagon infusion. Both are effective, albeit at the risk of hyperglycemia, but neither have been subjected to suitably powered randomized controlled trials to determine if they provide net benefit, i.e. less hypoglycemia without deterioration of glycemic control. As mentioned shortly, afternoon exercise is also a potential cause of nocturnal hypoglycemia $(1,2,49,54-57)$.

Exercise increases glucose utilization (by exercising muscle) but decrements in insulin and increments in glucagon normally prevent hypoglycemia [54]. Largely because insulin levels do not decrease, hypoglycemia occurs commonly during or shortly after exercise in people with T1DM $[54,55]$. While that risk is generally recognized, the risk of late post-exercise hypoglycemia [49,54-57] is less widely appreciated. Late post-exercise hypoglycemia in 
T1DM typically occurs 6 to 15 hours after strenuous exercise and is, therefore, often nocturnal [56]. In one study roughly half of youth with T1DM suffered nocturnal hypoglycemia following afternoon exercise whereas only about one quarter of that group suffered nocturnal hypoglycemia in the absence of afternoon exercise [49]. Exercise reduces sympathoadrenal responses to hypoglycemia several hours later in T1DM [54,57]. Thus, people with T1DM often develop exercise-related HAAF and suffer late post-exercise hypoglycemia $[1,2,54]$.

The vast majority of episodes of hypoglycemia in people with T1DM are iatrogenic, but those individuals can suffer from hypoglycemia caused by mechanisms other than insulin treatment [58].

Individualized Glycemic Goals-Given the benefits of glycemic control in T1DM $[3,4]$, mean glycemia as close to the nondiabetic range as can be accomplished safely is in the patient's best interest $[1,2]$. That is generally a $\mathrm{HbA}_{1 \mathrm{C}}$ of $<7.0 \%[59,60]$. However, while that goal often can be accomplished relatively early in T1DM [39], it is sometimes not possible to achieve that level without excessive hypoglycemia. It should be recalled that there is long-term benefit from reducing $\mathrm{HbA}_{1 \mathrm{C}}$ from higher to lower, although still above desirable, levels [61]. Ultimately, in individuals with limited life expectancy or functional capacity in whom glycemic control is unlikely to be beneficial [60,62], a higher glycemic goal becomes reasonable. Perhaps a reasonable generic goal is the lowest mean glycemia that causes no severe hypoglycemia, permits continued awareness of hypoglycemia and produces a tolerable number of episodes of symptomatic hypoglycemia.

Ongoing Professional Guidance and Support-Because the glycemic management of T1DM is empirical, caregivers should work with each individual patient over time to find the best methods of glycemic control for that individual at a given stage in the evolution of his or her diabetes [1,2]. Patient support is best provided by a team that includes professionals trained in, and dedicated to, translation of the standards of care [59] into the care of individual patients.

\section{Consider the Conventional Risk Factors for Hypoglycemia}

As discussed earlier, these include the dose, timing and type of the insulin preparations used, and conditions in which exogenous glucose delivery or endogenous glucose production is decreased, glucose utilization or insulin sensitivity is increased or insulin clearance is decreased $[1,2]$. They result in relative or absolute therapeutic hyperinsulinaemia. Each must be considered carefully when hypoglycemia is a real or a potential problem.

\section{Consider the Risk Factors Indicative of HAAF}

As detailed earlier, these include the degree of absolute endogenous insulin deficiency; a history of severe hypoglycemia; hypoglycemia unawareness, or both as well as a relationship between hypoglycemia and recent antecedent hypoglycemia, prior exercise or sleep; and lower glycemic goals [1,2]. The degree of endogenous insulin deficiency is, of course, beyond the caregiver's control. Unless the cause is readily correctable, a history of severe hypoglycemia should prompt a fundamental change in the regimen that will cause reduced insulin action, increased glucose availability, or both at the time of the earlier episode. Otherwise, the likelihood of another episode of severe hypoglycemia is high $[41,48]$. With a history of hypoglycemia unawareness, a 2- to 3-week trial of scrupulous avoidance of hypoglycemia is advisable since that may restore awareness [29-32]. When that was incorporated into a structured educational program, roughly half of the patients reported restored awareness of hypoglycemia one year later [63]. Finally, a history of nocturnal hypoglycemia, late post-exercise hypoglycemia, or both should prompt regimen 
adjustments that reduce insulin action, increase glucose availability, or both at the appropriate time.

\section{Treatment of Hypoglycemia in T1DM}

\section{Oral Self-Treatment}

Most episodes of asymptomatic or symptomatic hypoglycemia are effectively self-treated with glucose tablets or carbohydrate containing juice, soft drinks, candy, other snacks or a meal by the person with T1DM [1,2]. $20 \mathrm{~g}$, repeated in 15 to 20 minutes if necessary, is a reasonable dose of carbohydrate [64]. Since the glycemic response is transient [64], a subsequent more substantial snack or meal is generally advisable.

\section{Parenteral Treatment}

When a hypoglycemic patient is unable or, because of neuroglycopenia, unwilling to take carbohydrate orally, parenteral therapy is necessary. That is often glucagon injected subcutaneously or intramuscularly by an associate of the patient who has been trained to recognize severe hypoglycemia and treat it with glucagon. The usual glucagon dose of 1.0 $\mathrm{mg}$ in adults causes substantial, albeit transient, hyperglycemia [64] and can cause nausea or even vomiting. Smaller doses (e.g., $150 \mathrm{mcg}$ ), repeated if necessary, have been found to be effective without side effects in adolescents with T1DM [65]. Glucagon is ineffective in glycogen-depleted individuals (e.g., following a binge of alcohol ingestion). Intravenous glucose, $25 \mathrm{~g}$ initially, is the standard parenteral therapy in a medical setting. Because the response is transient, a subsequent intravenous glucose infusion is usually needed and a meal should be provided as soon as the patient is able to ingest it

\section{Summary of Recommendations}

Because mean glycemia as close to the nondiabetic range as can be accomplished safely is in the best interest of people with T1DM $\left(\mathrm{A}^{*}\right)$, it follows that caregivers should attempt to match insulin actions and circulating glucose availability at all times under all conditions so as to avoid severe hypoglycemia, hypoglycemia unawareness and intolerable symptomatic hypoglycemia while maintaining a meaningful degree of glycemic control ( $\left.\mathrm{B}^{*}\right)$. Thus, the following are recommended:

1. Acknowledge the problem of hypoglycemia in T1DM (B).

2. Apply the principles of aggressive glycemic therapy.

- Patient education and empowerment (B)

- Frequent SMBG (and in some instance continuous glucose sensing) (B)

- Flexible and appropriate insulin (and other) regimens including insulin analogues (A) and consideration of the special issues of nocturnal and early and late post-exercise hypoglycemia (B)

- Individualized glycemic goals (B)

- $\quad$ Ongoing professional guidance and support (B)

3. Consider the conventional risk factors for hypoglycemia in T1DM.

- Insulin dose, timing and type (A)

\footnotetext{
*The strength of the evidence supporting these recommendations is A for randomized controlled trials and meta-analysis and B for other evidence.
} 
- Glucose influx is decreased or efflux is increased (B)

- Sensitivity to insulin is increased or glucose clearance is decreased (B)

4. Consider the risk factors for hypoglycemia-associated autonomic failure (HAAF) in T1DM.

- The degree of endogenous insulin deficiency (B)

- A history of severe hypoglycemia, hypoglycemia unawareness, or both as well as any relationship with recent antecedent hypoglycemia, prior exercise or sleep (B)

- Lower HbA1C levels (A)

While this approach will likely become more successful as more is learned about the mechanisms of hypoglycemia in T1DM, elimination of hypoglycemia from the lives of people with T1DM will probably be accomplished by the development of new treatment methods that provide plasma glucose regulated insulin replacement or secretion.

\section{Acknowledgments}

The author is grateful for the contributions of postdoctoral fellows and the skilled nursing, technical, dietary and data management/statistical assistance of the staff of the Washington University General Clinical Research Center. Ms. Janet Dedeke prepared this manuscript.

The author's original research cited was supported, in part, by National Institutes of Health grants R37 DK27085, MO1 RR00036 (now UL1 RR24992), P60 DK20579, and T32 DK07120 and a fellowship award from the American Diabetes Association.

\section{References}

1. Cryer PE. The barrier of hypoglycemia in diabetes. Diabetes 2008;57(12):3169-76. [PubMed: 19033403]

2. Cryer, PE. Pathophysiology, Prevalence and Prevention. American Diabetes Association; Alexandria, VA: 2009. Hypoglycemia in Diabetes.

3. The Diabetes Control and Complications Trial Research Group. The effect of intensive treatment of diabetes on the development and progression of long-term complications in insulin-dependent diabetes mellitus. N Engl J Med 1993;329(14):977-86. [PubMed: 8366922]

4. Diabetes Control and Complications Trial/Epidemiology of Diabetes Interventions and Complications (DCCT/EDIC) Study Research Group. Intensive diabetes treatment and cardiovascular disease in patients with type 1 diabetes. N Engl J Med 2005;353(25):2643-53. [PubMed: 16371630]

5. Juvenile Diabetes Research Foundation Continuous Glucose Monitoring Study Group. The effect of continuous glucose monitoring in well-controlled type 1 diabetes. Diabetes Care 2009;32(8):137883. [PubMed: 19429875]

6. Raju B, Arbelaez AM, Breckenridge SM, et al. Nocturnal hypoglycemia in type 1 diabetes: an assessment of preventive bedtime treatments. J Clin Endocrinol Metab 2006;91(6):2087-92. [PubMed: 16492699]

7. DeRosa MA, Cryer PE. Hypoglycemia and the sympathoadrenal system: neurogenic symptoms are largely the result of sympathetic neural, rather than adrenomedullary, activation. Am J Physiol Endocrinol Metab 2004;287(1):E32-41. [PubMed: 14970007]

8. Towler DA, Havlin CE, Craft S, et al. Mechanism of awareness of hypoglycemia. Perception of neurogenic (predominantly cholinergic) rather than neuroglycopenic symptoms. Diabetes 1993;42(12):1791-8. [PubMed: 8243825]

9. Boyle PJ, Schwartz NS, Shah SD, et al. Plasma glucose concentrations at the onset of hypoglycemic symptoms in patients with poorly controlled diabetes and in nondiabetics. N Engl J Med 1988;318(23):1487-92. [PubMed: 3285214] 
10. Amiel SA, Sherwin RS, Simonson DC, et al. Effect of intensive insulin therapy on glycemic thresholds for counterregulatory hormone release. Diabetes 1988;37(7):901-7. [PubMed: 3290007]

11. Cryer PE. Hypoglycemia, functional brain failure, and brain death. J Clin Invest 2007;117(4):86870. [PubMed: 17404614]

12. Heller SR. Sudden death and hypoglycaemia. Diabetic Hypoglycaemia 2008;1(2):2-7. www.hypodiab.com.

13. Adler GK, Bonyhay I, Failing H, et al. Antecedent hypoglycemia impairs autonomic cardiovascular function: implications for rigorous glycemic control. Diabetes 2009;58(2):360-6. [PubMed: 19056608]

14. Diabetes Control and Complications Trial/Epidemiology of Diabetes Interventions and Complications Study Research Group. Long-term effect of diabetes and its treatment on cognitive function. N Engl J Med 2007;356(18):1842-52. [PubMed: 17476010]

15. Feltbower RG, Bodansky HJ, Patterson CC, et al. Acute complications and drug misuse are important causes of death for children and young adults with type 1 diabetes: results from the Yorkshire Register of diabetes in children and young adults. Diabetes Care 2008;31(5):922-6. [PubMed: 18285550]

16. Skrivarhaug T, Bangstad HJ, Stene LC, et al. Long-term mortality in a nationwide cohort of childhood-onset type 1 diabetic patients in Norway. Diabetologia 2006;49(2):298-305. [PubMed: 16365724]

17. American Diabetes Association Workgroup on Hypoglycemia. Defining and reporting hypoglycemia in diabetes. Diabetes Care 2005;28(5):1245-9. [PubMed: 15855602]

18. Cryer PE. Preventing hypoglycaemia: what is the appropriate glucose alert value? Diabetologia 2009;52(1):35-7. [PubMed: 19018509]

19. Cryer, PE. The prevention and correction of hypoglycemia. In: Jefferson, LS.; Cherrington, AD., editors. Handbook of Physiology. Section 7, The Endocrine System. Vol. Volume II, The Endocrine Pancreas and Regulation of Metabolism. Oxford University Press; New York: 2001. p. 1057-92.

20. Cryer PE. Mechanisms of sympathoadrenal failure and hypoglycemia in diabetes. J Clin Invest 2006;116(6):1470-3. [PubMed: 16741570]

21. Dagogo-Jack SE, Craft S, Cryer PE. Hypoglycemia-associated autonomic failure in insulindependent diabetes mellitus. J Clin Invest 1993;91(3):819-28. [PubMed: 8450063]

22. Gerich JE, Langlois M, Noacco C, et al. Lack of glucagon response to hypoglycemia in diabetes: evidence for an intrinsic pancreatic alpha cell defect. Science 1973;182(108):171-3. [PubMed: 4581053]

23. Raju B, Cryer PE. Loss of the decrement in intraislet insulin plausibly explains loss of the glucagon response to hypoglycemia in insulin-deficient diabetes. Diabetes 2005;54(3):757-64. [PubMed: 15734853]

24. Cooperberg BA, Cryer PE. Beta-cell-mediated signaling predominates over direct alpha-cell signaling in the regulation of glucagon secretion in humans. Diabetes Care 2009;32(12):2275-80. [PubMed: 19729529]

25. Heller SR, Cryer PE. Reduced neuroendocrine and symptomatic responses to subsequent hypoglycemia after 1 episode of hypoglycemia in nondiabetic humans. Diabetes 1991;40(2):2236. [PubMed: 1991573]

26. White NH, Skor DA, Cryer PE, et al. Identification of type I diabetic patients at increased risk for hypoglycemia during intensive therapy. N Engl J Med 1983;308(9):485-91. [PubMed: 6337335]

27. Bolli GB, De Feo P, De Cosmo S, et al. A reliable and reproducible test for adequate glucose counterregulation in type I diabetes mellitus. Diabetes 1984;33(8):732-7. [PubMed: 6378698]

28. Geddes J, Schopman JE, Zammitt NN, et al. Prevalence of impaired awareness of hypoglycaemia in adults with Type 1 diabetes. Diabet Med 2008;25(4):501-4. [PubMed: 18387080]

29. Fanelli CG, Epifano L, Rambotti AM, et al. Meticulous prevention of hypoglycemia normalizes the glycemic thresholds and magnitude of most of neuroendocrine responses to, symptoms of, and cognitive function during hypoglycemia in intensively treated patients with short-term IDDM. Diabetes 1993;42(11):1683-9. [PubMed: 8405713] 
30. Fanelli C, Pampanelli S, Epifano L, et al. Long-term recovery from unawareness, deficient counterregulation and lack of cognitive dysfunction during hypoglycaemia, following institution of rational, intensive insulin therapy in IDDM. Diabetologia 1994;37(12):1265-76. [PubMed: 7895957]

31. Cranston I, Lomas J, Maran A, et al. Restoration of hypoglycaemia awareness in patients with long-duration insulin-dependent diabetes. Lancet 1994;344(8918):283-7. [PubMed: 7914259]

32. Dagogo-Jack S, Rattarasarn C, Cryer PE. Reversal of hypoglycemia unawareness, but not defective glucose counterregulation, in IDDM. Diabetes 1994;43(12):1426-34. [PubMed: 7958494]

33. Arbelaez AM, Powers WJ, Videen TO, et al. Attenuation of counterregulatory responses to recurrent hypoglycemia by active thalamic inhibition: a mechanism for hypoglycemia-associated autonomic failure. Diabetes 2008;5(2):470-5. [PubMed: 18003752]

34. Cryer PE, Davis SN, Shamoon H. Hypoglycemia in diabetes. Diabetes Care 2003;26(6):1902-12. [PubMed: 12766131]

35. The Diabetes Control and Complications Trial Research Group. Epidemiology of severe hypoglycemia in the diabetes control and complications trial. Am J Med 1991;90(4):450-9. [PubMed: 2012085]

36. Davis S, Alonso MD. Hypoglycemia as a barrier to glycemic control. J Diabetes Complications 2004;18(1):60-8. [PubMed: 15019602]

37. Rossetti P, Porcellati F, Bolli GB, et al. Prevention of hypoglycemia while achieving good glycemic control in type 1 diabetes: the role of insulin analogs. Diabetes Care 2008;31(Suppl 2):S113-20. [PubMed: 18227470]

38. Gonder-Frederick LA, Fisher CD, Ritterband LM, et al. Predictors of fear of hypoglycemia in adolescents with type 1 diabetes and their parents. Pediatr Diabetes 2006;7(4):215-22. [PubMed: 16911009]

39. The UK Hypoglycaemia Study Group. Risk of hypoglycaemia in types 1 and 2 diabetes: effects of treatment modalities and their duration. Diabetologia 2007;50(6):1140-7. [PubMed: 17415551]

40. Cox DJ, Kovatchev B, Koev D, et al. Hypoglycemia anticipation, awareness and treatment training (HAATT) reduces occurrence of severe hypoglycemia among adults with type 1 diabetes mellitus. Int J Behav Med 2004;11(4):212-8. [PubMed: 15657021]

41. Cox DJ, Gonder-Frederick L, Ritterband L, et al. Prediction of severe hypoglycemia. Diabetes Care 2007;30(6):1370-3. [PubMed: 17363757]

42. Juvenile Diabetes Research Foundation Continuous Glucose Monitoring Study Group. Continuous glucose monitoring and intensive treatment of type 1 diabetes. N Engl J Med 2008;359(14):146476. [PubMed: 18779236]

43. Hirsch IB. Insulin analogues. N Engl J Med 2005;352(2):174-83. [PubMed: 15647580]

44. Gough SCL. A review of human and analogue insulin trials. Diabetes Research and Clinical Practice 2007;77(1):1-15. [PubMed: 17112621]

45. Fatourechi MM, Kudva YC, Murad MH, et al. Hypoglycemia with intensive insulin therapy: a systematic review and meta-analyses of randomized trials of continuous subcutaneous insulin infusion versus multiple daily injections. J Clin Endocrinol Metab 2009;94(3):729-40. [PubMed: 19088167]

46. Bolli GB, Kerr D, Thomas R, et al. Comparison of a multiple daily insulin injection regimen (basal once-daily glargine plus mealtime lispro) and continuous subcutaneous insulin infusion (lispro) in type 1 diabetes: a randomized open parallel multicenter study. Diabetes Care 2009;32(7):1170-6. [PubMed: 19389820]

47. Mukhopadhyay A, Farrell T, Fraser RB, et al. Continuous subcutaneous insulin infusion vs intensive conventional insulin therapy in pregnant diabetic women: a systematic review and metaanalysis of randomized, controlled trials. Am J Obstet Gynecol 2007;197(5):447-56. [PubMed: 17678864]

48. The Diabetes Control and Complications Trial Research Group. Hypoglycemia in the Diabetes Control and Complications Trial. Diabetes 1997;46(2):271-86. [PubMed: 9000705]

49. Tsalikian E, Mauras N, Beck RW, et al. Diabetes Research In Children Network DirecNet Study Group. Impact of exercise on overnight glycemic control in children with type 1 diabetes mellitus. J Pediatr 2005;147(4):528-34. [PubMed: 16227041] 
50. Jones TW, Porter P, Sherwin RS, et al. Decreased epinephrine responses to hypoglycemia during sleep. N Engl J Med 1998;338(23):1657-62. [PubMed: 9614256]

51. Banarer S, Cryer PE. Sleep-related hypoglycemia-associated autonomic failure in type 1 diabetes: reduced awakening from sleep during hypoglycemia. Diabetes 2003;52(5):1195-203. [PubMed: 12716752]

52. Schultes B, Jauch-Chara K, Gais S, et al. Defective awakening response to nocturnal hypoglycemia in patients with type 1 diabetes mellitus. PLoS Med 2007;4(2):e69. [PubMed: 17326710]

53. Cooperberg BA, Breckenridge SM, Arbelaez AM, et al. Terbutaline and the prevention of nocturnal hypoglycemia in type 1 diabetes. Diabetes Care 2008;31(12):2271-2. [PubMed: 18782903]

54. Ertl AC, Davis SN. Evidence for a vicious cycle of exercise and hypoglycemia in type 1 diabetes mellitus. Diabetes Metab Res Rev 2004;20(2):124-30. [PubMed: 15037987]

55. Tansey MJ, Tsalikian E, Beck RW, et al. Diabetes Research in Children Network (DirecNet) Study Group. The effects of aerobic exercise on glucose and counterregulatory hormone concentrations in children with type 1 diabetes. Diabetes Care 2006;29(1):20-5. [PubMed: 16373890]

56. MacDonald MJ. Postexercise late-onset hypoglycemia in insulin-dependent diabetic patients. Diabetes Care 1987;10(5):584-8. [PubMed: 3677976]

57. Sandoval DA, Guy DL, Richardson MA, et al. Effects of low and moderate antecedent exercise on counterregulatory responses to subsequent hypoglycemia in type 1 diabetes. Diabetes 2004;53(7): 1798-806. [PubMed: 15220204]

58. Cryer PE, Axelrod L, Grossman AB, et al. Evaluation and management of adult hypoglycemic disorders: an Endocrine Society Clinical Practice Guideline. J Clin Endocrinol Metab 2009;94(3): 709-28. [PubMed: 19088155]

59. American Diabetes Association. Standards of medical care in diabetes--2009. Diabetes Care 2009;32(Suppl 1):S13-61. [PubMed: 19118286]

60. Skyler JS, Bergenstal R, Bonow RO, et al. Intensive glycemic control and the prevention of cardiovascular events: implications of the ACCORD, ADVANCE, and VA diabetes trials. Diabetes Care 2009;32(1):187-92. [PubMed: 19092168]

61. Lachin JM, Genuth S, Nathan DM, et al. for the DCCT/EDIC Research Group. Effect of glycemic exposure on the risk of microvascular complications in the diabetes control and complications trial: revisited. Diabetes 2008;57(4):995-1001. [PubMed: 18223010]

62. Huang ES, Zhang Q, Gandra N, et al. The effect of comorbid illness and functional status on the expected benefits of intensive glucose control in older patients with type 2 diabetes: a decision analysis. Ann Intern Med 2008;149(1):11-9. [PubMed: 18591633]

63. Hopkins D, Lawrence I, Mansell P, et al. Routine structured education reduces HbA1C and hypoglycemia and improves psychological health in patients with type 1 diabetes mellitus (abstract). Diabetes 2008;57(Suppl 1):A37.

64. Wiethop BV, Cryer PE. Alanine and terbutaline in treatment of hypoglycemia in IDDM. Diabetes Care 1993;16(8):1131-6. [PubMed: 8375243]

65. Haymond MW, Schreiner B. Mini-dose glucagon rescue for hypoglycemia in children with type 1 diabetes. Diabetes Care 2001;24(4):643-5. [PubMed: 11315823] 


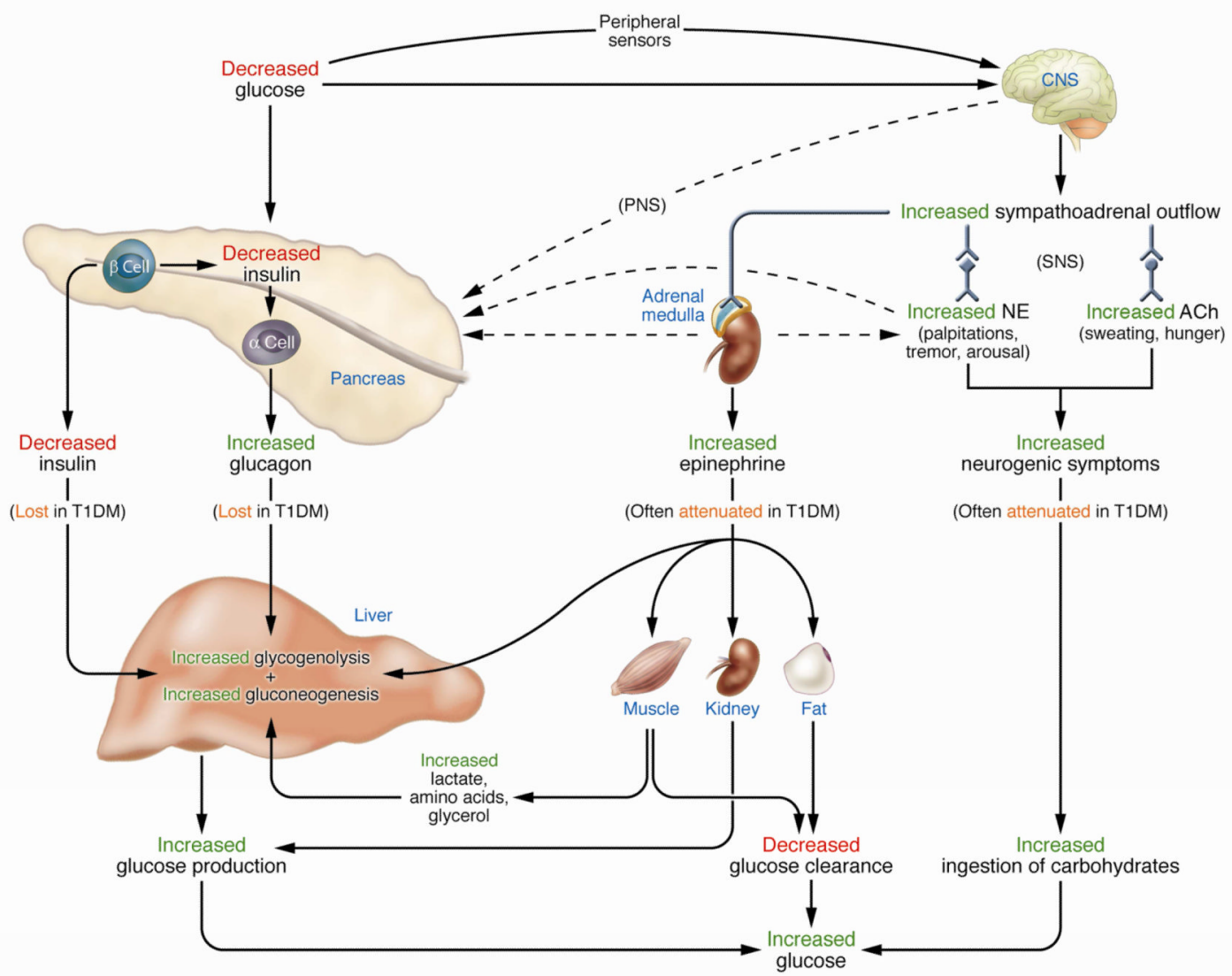

Figure 1.

Physiological and behavioral defenses against hypoglycemia in humans and their compromise in people with T1DM. ACh, acetylcholine; NE, norepinephrine; PNS, parasympathetic nervous system; SNS, sympathetic nervous system. From Cryer PE. Mechanisms of sympathoadrenal failure and hypoglycemia in diabetes. J Clin Invest 2006;116(6):1471, with permission of the American Society for Clinical Investigation. 


\section{Hypoglycemia-Associated Autonomic Failure}

\author{
Early T2DM \\ (Relative $\beta$-Cell Failure) \\ I \\ Marked Absolute Therapeutic \\ Hyperinsulinemia \\ Falling Glucose Levels \\ Isolated Episodes
of Hypoglycemia
}

Advanced T2DM and T1DM

(Absolute $\beta$-Cell Failure)

I

Relative or Mild-Moderate Absolute

Therapeutic Hyperinsulinemia

Falling Glucose Levels

I

$\beta$-Cell Failure $\rightarrow$ No $\downarrow$

Figure 2.

Schematic diagram of defective glucose counterregulation and hypoglycemia unawareness, and the unifying concept of hypoglycemia-associated autonomic failure, in T1DM. From Cryer PE. Exercise-related hypoglycemia-associated autonomic failure. Diabetes 2009;58(9):1952, with permission of the American Diabetes Association. 